Artigo original

Hegemonia - Revista Eletrônica do Programa de Mestrado em Direitos Humanos, Cidadania e Violência/Ciência Política do Centro Universitário Unieuro

ISSN: 1809-1261

UNIEURO, Brasília, número 26, Janeiro a Junho de 2019, pp. 4-29.

Recebido em: 3/08/2018

Avaliado em: $1 / 10 / 2018$

Aprovado em: 12/11/2018

\title{
DESAFIOS PARA UMA EDUCAÇÃO EM DIREITOS HUMANOS NO
}

\author{
BRASIL
}

Ana da Costa Polonia ${ }^{1}$ e Marden Marques Soares Filho ${ }^{2}$

Resumo: Os Direitos Humanos foram elaborados pela Organização das Nações Unidas em 1945, com base na Declaração Universal dos Direitos Humanos, o Pacto Internacional dos Direitos Civis e Políticos e o Pacto Internacional dos Direitos Econômicos, Sociais e Culturais. A educação em direitos humanos se constitui como um dos eixos que garante o direito à educação por meio de práticas, conteúdos, vivências e difusão de valores que permeiam os processos de promoção, defesa, proteção e o emprego de seus princípios fundamentais na vida, no trabalho, nas relações interpessoais. O objetivo deste artigo é promover a reflexão sobre a Educação em Direitos Humanos, tendo como o lócus a instituição escolar. A ação conjunta, intersetorial e multissetorial com escolas e distintas instituições e órgão nacionais e internacionais (justiça, trabalho, organizações não governamentais, etc) deve ser implementada, em virtude de ser uma tarefa tão complexa incrementar e assegurar a educação em direitos humanos.

Palavras-chave: educação em direitos humanos, instituição escolar, ações em parceria

Abstract: Human Rights were elaborated by the United Nations in 1945 on the basis of the Universal Declaration of Human Rights, the International Covenant on Civil and Political Rights and the International Covenant on Economic, Social and Cultural Rights. Human Rights Education is one of the axes that guarantees the right to education through practices, contents, experiences and diffusion of values that permeate the process of promotion, defense, protection and employment of its fundamental principles in life, work, and interpersonal relationships. The objective of this article is to promote reflection on Human Rights Education, having as the lócus to the school institution. It is essential to promote the collaboration between schools and different national and international institutions(justice, labor, non-governmental organizations, etc.) and it should be implemented, since it is such a complex task to increase and ensure Human Rights Education.

Keywords: human rights education, educational institution, partnership actions

\footnotetext{
${ }^{1}$ Doutora em Psicologia e professora do Centro Universitário Euro-Americano.

2 Mestre em Ciência Política e professor do Centro Universitário Euro Americano-Unieuro.
} 
Artigo original

Hegemonia - Revista Eletrônica do Programa de Mestrado em Direitos Humanos, Cidadania e Violência/Ciência Política do Centro Universitário Unieuro

ISSN: $1809-1261$

UNIEURO, Brasília, número 26, Janeiro a Junho de 2019, pp. 4-29.

Apresentando a proposta

Os direitos humanos conhecidos na atualidade foram elaborados pela Organização das Nações Unidas (ONU) em 1945, como aponta Oliveira (2017), assim como diversos outros tratados e normas internacionais, que começaram a proteger os direitos humanos contra o próprio Estado, tendo como principais instrumentos a Declaração Universal dos Direitos Humanos, o Pacto Internacional dos Direitos Civis e Políticos e o Pacto Internacional dos Direitos Econômicos, Sociais e Culturais.

Esses instrumentos normativos adotaram uma nova concepção de direitos humanos, como universais, indivisíveis e interdependentes. Ainda para Oliveira (2017), os direitos civis e políticos formam com os direitos econômicos, sociais e culturais uma unidade indivisível e interdependente, sendo que os países do mundo, signatários dos direitos humanos, devem tratar seus cidadãos nesta perspectiva e o Brasil tem tentado se afinar com as políticas internacionais, resgatando a preocupação com as minorias, não apenas no sentido do seu reconhecimento, todavia, investindo nos espaços de participação, envolvimento e de proposição de políticas.

Nesse sentido, a discussão sobre os direitos humanos tem se delineado em vários contextos o educacional, social, político, econômico, moral e ético, ambiental, além de análise da sua trajetória histórica e dos movimentos atuais para sua garantia. A questão da diferença, diversidade e da inclusão são paradigmas que tem permeado o debate, sobretudo, por meio do resgate do ser humano em sua complexidade quando se aborda a temática. Ainda, está atrelado ao reconhecimento das minorias e de sua exclusão social, levantando o manto da invisibilidade de grupos, em âmbito nacional ou mundial. Barreiro, Farias e Santos (2011) destacam o papel da educação, apontando como um dos ambientes que contribuem para o desenvolvimento pessoal, profissional e em especial voltado a humanização e o espaço de cidadania. Ampliando essa 
Artigo original

Hegemonia - Revista Eletrônica do Programa de Mestrado em Direitos Humanos, Cidadania e Violência/Ciência Política do Centro Universitário Unieuro

ISSN: 1809-1261

UNIEURO, Brasília, número 26, Janeiro a Junho de 2019, pp. 4-29.

perspectiva, Pessoa, Santa e Carvalho (2017) ressaltam que a Educação em Direitos Humanos é um elemento essencial a ser implementado nos espaços de educação formal e não formal, em prol da sua condição fundamental para a democracia em seu sentido mais amplo, tendo como requisito a dignidade da pessoa humana.

Nessa direção, o governo brasileiro tem o compromisso de promover uma educação de qualidade para todos, entendida como direito humano essencial, universalizando o ensino fundamental, ampliando a educação infantil, o ensino médio, a educação superior e primando pela melhoria da qualidade em todos esses níveis e nas diversas modalidades de ensino. ${ }^{3}$ Além disso,

\begin{abstract}
é dever dos governos democráticos garantir a educação de pessoas com necessidades especiais, a profissionalização de jovens e adultos, a erradicação do analfabetismo e a valorização dos(as) educadores(as) da educação, da qualidade da formação inicial e continuada, tendo como eixos estruturantes o conhecimento e a consolidação dos direitos humanos (PNEDH, 2008, p.11).
\end{abstract}

A Educação em Direitos Humanos se constitui, então, como um dos eixos que garante o direito à educação, assegurada por práticas, conteúdos, vivências e difusão de valores que permeiam os processos de promoção, defesa, proteção e o emprego de seus princípios fundamentais na vida, no trabalho, nas relações interpessoais. É um desafio que envolve não apenas a concepção individual, mas a esfera da vida coletiva sobrepujando a concepção individualista e isolada das responsabilidades individuais, com apregoa Resolução no 1, de 30 de maio de 2012 que implanta as Diretrizes Nacionais para a Educação em Direitos Humanos.

Candau e Sacavino (2013, p. 60 apud PESSOA, SANTOS, CARVALHO, 2017) alertam que não é uma fundamentação jurídica que vai assegurar e incrementar o paradigma dos Direitos Humanos na sociedade, pelo contrário, é essencial mudar o imaginário social, e um dos espaços que pode acioná-lo é o contexto educacional. Neste sentido, a questão da democracia transita pelo

\footnotetext{
3 http://portal.mec.gov.br/index.php?option=com_docman\&view=download\&alias=2191-plano-nacionalpdf\&category_slug=dezembro-2009-pdf\&Itemid=30192
} 
Artigo original

Hegemonia - Revista Eletrônica do Programa de Mestrado em Direitos Humanos, Cidadania e Violência/Ciência Política do Centro Universitário Unieuro

ISSN: $1809-1261$

UNIEURO, Brasília, número 26, Janeiro a Junho de 2019, pp. 4-29.

cotidiano, na possibilidade de lidar com as diferenças, inclusão e a diversidade como aspectos inerentes aos serem humanos, bem como os conflitos peculiares a qualquer processo, contudo com uma ação mediativa dos sujeitos e da coletividade.

Neste sentido, Sandoval (2014) defende que uma educação de valores pode contribuir significativamente à promoção dos direitos humanos, e aponta o significado psicossocioeducativo para incrementá-los no espaço escolar. Ele postula que os valores são dimensões que mantém a coesão social, permitem à compreensão dos comportamentos e ainda possibilitam o compartilhamento do Ethos que permeia a vida cotidiana. Ele resgata que os valores outorgam significados ao conjunto de referências que orientam os comportamentos e relações interpessoais com a sociedade e o mundo. Assim, tanto o indivíduo, o grupo social a que pertence e a comunidade em geral lidam com algum tipo de ordenamento os valores que sustentam e explicam as condutas do ser humano.

Ampliando a discussão, Tardif (2014) afirma que a escola tem um papel fundamental na sociedade letrada e globalizada, e que não está somente baseada no desenvolvimento cognitivo, mas afetivo, social, cultural e de valores em seu seio. Cardoso (2014) sustenta que a educação integra per se e reflete o agregado dos direitos humanos considerados como essenciais: econômicos, sociais e culturais. A educação se inclui em um direito social, postulado pelo autor, já que é imprescindível à vida em sociedade e não pode ser entendido como um coletivo, pois não se vincula as reivindicações de ordem da justiça social.

Costa (2013) reverbera a condição da escola, enfatizando que o espaço escolar abarca a diversidade e as diferenças, sendo um grande celeiro para os desafios ao lidar com as distintas culturas, hábitos, costumes, crenças, valores e comportamentos peculiares aos grupos sociais que compões os países. Wenceslau e Silva (2017) realizaram um estudo em que enfocou os mecanismos de identificação de currículos em prol das transformações sociais, identificando por meio das práticas educativas e curriculares, a questão da diversidade e sob a égide da emancipação, o respeito 
Artigo original

Hegemonia - Revista Eletrônica do Programa de Mestrado em Direitos Humanos, Cidadania e Violência/Ciência Política do Centro Universitário Unieuro

ISSN: 1809-1261

UNIEURO, Brasília, número 26, Janeiro a Junho de 2019, pp. 4-29.

e, principalmente, uma educação para transformação social embasada na cidadania e na coletividade. Isso acontece, por meio de práticas que incluem a noção de construção da cidadania, o respeito, a ética, a estética, a participação, o compartilhamento e a consciência do coletivo como um fator humano.

No que diz respeito aos direitos humanos e o ensino superior, Petry (2015) renova a demanda sobre a responsabilidade social e, paralelamente, a função das instituições de ensino superior em investir, desenvolver e promover a concepção de direitos humanos, em uma perspectiva educacional, para a construção de um mundo melhor, a partir da convivência com a diversidade e a inclusão. A dignidade humana deve ser uma experiência vivida no espaço educacional, acionada com um tema transversal, assumida e difundida por todos, corroborada pelas relações entre os professores, alunos, conteúdos, situações de aprendizagem e de ensino. Associada à temática se encontram a questão ética, estética e assim, necessitando de reflexões contínuas sobre o ser humano nos distintos espaços que ocupa e da maneira que interage com os outros: família, escola, trabalho, vizinhança, tornam-se essenciais.

O autor supracitado alerta que apesar dos direitos humanos serem compreendidos como um bem cultural da humanidade, muito ainda se precisa avançar, no sentindo de que na modernidade a exclusão, a visão negativa das minorias, e ainda da intolerância racial, religiosa, cultural perduram no âmago das sociedades. A desvalorização do ser humano, a sua desqualificação e o discurso de exclusão estão presentes e justificados por atitudes que apontam corriqueiramente essa ação. Quando se incrementou no país as ações afirmativas, por exemplo, o sistema de cota gerou uma grande discussão para inibir o processo na ascensão dos negros, indígenas e estudantes de escola pública à universidade pública. Os discursos repletos de preconceito e de desqualificação tentavam fundamentar seus 'argumentos' baseados no senso comum, essencialmente, que a universidade pública teria uma queda na sua qualidade, por inserir esses grupos em seu currículo escolar ou que isso retirava o direito de outros, com melhores notas. 
Artigo original

Hegemonia - Revista Eletrônica do Programa de Mestrado em Direitos Humanos, Cidadania e Violência/Ciência Política do Centro Universitário Unieuro

ISSN: 1809-1261

UNIEURO, Brasília, número 26, Janeiro a Junho de 2019, pp. 4-29.

Nesse sentido, Wainer e Melguizo (2018) registram que há três tipos de inclusão e de ações afirmativas no ensino superior: política de cota, de bolsa (Programa de Universidade para TodosProUni) e empréstimos nas instituições privadas (Financiamento Estudantil-Fies) ${ }^{4}$. A primeira está direcionada aos grupos considerados desprivilegiados, no caso, os critérios de raça ou condição social, a segunda revela a política de bolsa para alunos desfavorecidos. Como reiterado pelas as análises dos pesquisadores supracitados, o que se constata hoje é que não existem diferenças entre o conhecimento dos alunos cotistas e não contistas no final do curso, tendo como referência o Enade (Exame Nacional de Desempenho dos Estudantes), no que se refere às habilidades gerais como aos conhecimentos específicos.

Deve-se refletir que o papel da universidade é desenvolver os conhecimentos científicos, técnicos, metodológicos, éticos, estéticos e uma educação de direitos humanos, alicerçada na inclusão e diversidade que são princípios universais. A escola tem um papel diferenciado nessa formação do sujeito, da coletividade e das transformações internas e externas, sendo responsável pela aprendizagem e a promoção dos conhecimentos, saberes, valores, culturas em seu seio.

Educação e Direitos Humanos: interfaces e conceitos estruturantes

Ao se buscar as interfaces entre educação e direitos humanos, Costa (2013) em sua proposta educacional indica os seguintes pressupostos e conceitos que subsidiam a discussão: noção de alteridade, diversidade, multiculturalismo, interculturalidade e a concepção de identidade cultural. É preciso reiterar que não são conceitos estanques e nem desarticulados, porque merecem uma leitura contextualizada e integrada de seus princípios na educação. Desta forma, é importante

\footnotetext{
${ }^{4}$ Não é o intuito deste texto discutir as políticas de inclusão e ações afirmativas no ensino superior, apenas ilustrar o contexto.
} 
Artigo original

Hegemonia - Revista Eletrônica do Programa de Mestrado em Direitos Humanos, Cidadania e Violência/Ciência Política do Centro Universitário Unieuro

ISSN: 1809-1261

UNIEURO, Brasília, número 26, Janeiro a Junho de 2019, pp. 4-29.

retomar os conceitos e compreendê-los como se constituem no espaço escolar e do cotidiano das pessoas. Em virtude de um viés didático é preciso separá-los para um entendimento balizado do leitor e considerando que é uma escolha dos autores deste artigo, em função de outras categorias reconhecidas pesquisadas no âmbito educativo.

Educação e o lócus da alteridade

Sobre o espaço pedagógico, Meneghetti (2015) enfatiza que a atividade educacional deve estimular o senso crítico, a ética e estética, favorecendo o autoconhecimento e como bem estar individual e a noção coletiva, defendido por Wallon (2008), quando discute a indissociabilidade entre o par dialético indivíduo-sociedade. O desafio é possibilitar os sujeitos a identificar, considerar e reconhecer como potencial as diferenças, tanto suas como de seus coetâneos, assegurando como uma condição inalienável do ser humano. Assim, a alteridade emerge como um vetor que fomenta o reconhecimento das diferenças e o outro, nas relações interpessoais, não sendo percebido como um estranho e nem exótico, evidenciado com ares de desqualificação e exclusão do ambiente social.

Jodelet (1999) indica que a alteridade faz parte da dinâmica psicossocial, ao mesmo tempo conjugando a exclusão e a construção social que constituem às representações sociais. Ela, então, contribui sublinhando que há uma "alteridade de fora” representada pelo diferente e o exótico com relação a uma determinada cultura e a "alteridade de dentro", que emergem no próprio grupo social ou cultural. Por exemplo, o abraço comum na cultura brasileira que não existe em outros países, aparece invasivo aos estrangeiros e 'assustador' no primeiro momento; no segundo exemplo, os transtornos mentais, hoje tão em evidência como a depressão. Por vezes, associadas a uma representação de fraqueza, de falta de fé em Deus, e 'fricote'. 
Artigo original

Hegemonia - Revista Eletrônica do Programa de Mestrado em Direitos Humanos, Cidadania e Violência/Ciência Política do Centro Universitário Unieuro

ISSN: $1809-1261$

UNIEURO, Brasília, número 26, Janeiro a Junho de 2019, pp. 4-29.

Enfim, a alteridade está subjacente à percepção das diferenças, contudo, deve-se realçar que elas são fontes inestimáveis da riqueza do ser humano, da distinção e da noção que cada um é único no universo. E no que tange a educação, uma de suas finalidades é o desenvolvimento do sujeito em toda sua plenitude e dignidade, na asserção da alteridade como um direito inalienável.

Pereira (2016) enriquece a discussão, contextualizando que no século XXI a intensa discussão sobre a diversidade cultural, e a questão da interculturalidade se tornaram fontes de investigação, reflexão em virtude das mudanças sociais. Caracterizadas pelas dinâmicas provenientes da globalização, em virtude dos conflitos entre grupos e países, como na guerra e, revestida na ação de intolerância, mas por outro lado, gerando o intercâmbio de riqueza de culturas, sobrepujando a mítica 'torre de babel' pelo diálogo e superação das idiossincrasias, considerando a criatividade e a multiplicidade dos seres humanos em sua expressão como grupo e sociedade. Assim, a instituição escolar por sua condição agrega a diversidade dos grupos sociais, culturais, e das mais distintas formas de expressão, sentimentos e sentidos, e com reporta Lima (2009), é o verdadeiro 'lócus da diversidade social'.

A instituição escolar como um contexto de desenvolvimento humano (BROFENBRENNER, 2005), não pode se limitar as questões em nível operatório, mas integrar os diversos aspectos inerentes ao ser humano. Desde os contextos micro ao macro (da família à questões da globalização) em distintos contextos sociais, aos problemas que atingem o mundo como a comunidade mais próxima.

Multiculturalismo crítico e interculturalidade

Multiculturalismo e interculturalidade são conceitos que contribuem significativamente para compreensão e ampliação das noções ligadas à educação em direitos humanos. Quanto ao 
Artigo original

Hegemonia - Revista Eletrônica do Programa de Mestrado em Direitos Humanos, Cidadania e Violência/Ciência Política do Centro Universitário Unieuro

ISSN: $1809-1261$

UNIEURO, Brasília, número 26, Janeiro a Junho de 2019, pp. 4-29.

multiculturalismo é fundamental destacar que são formas e padrões de abordar à diversidade étnica, de classe social, gênero, linguística, cultural, intergeracional, sexual, religiosa, das deficiências, como identificada MacLaren (1997). Neste texto, prefere-se enfocar o multiculturismo crítico, frentes os diversos modelos adotados, como defendido por Neira (2016), que tem fundamentação na teoria crítica cujo objetivo está vinculado como se produz e reproduz a dominação, nos diversos contextos de vida.

E nesse sentido, sua proposta não é de minimizar as crises, escamotear a diferenças e nem negar os conflitos, afinal são fontes de informação e vetores para as transformações sociais. Em suma, a necessidade de promover estratégias para manejar as questões cotidianas individuais e coletivas que são imprescindíveis para o espaço da reflexão individual, coletiva e o respeito à subjetividade, intersubjetividade e transubjetividade. Essencialmente, envolvendo os conflitos, às diferenças e as revelando como fatores que são prejudiciais às pessoas e suas relações.

Neira (2016) afirma que a pedagogia multicultural crítica não assume a neutralidade como um aspecto da sua proposta, muito pelo contrário, prefere expor os valores e crenças que subsidiam suas práticas. No cerne do seu pressuposto a equidade, a eliminação do sofrimento humano em todas as suas dimensões, como um imperativo ético, sobretudo que, a desigualdade de classe é uma preocupação crucial no multiculturalismo crítico, postulado por Kincheloe e Steinberg (2012 apud NEIRA, 2016).

Costa e Soares (2015), ao resgatar as proposições de Rawl, difundidas em 1971, afirmam que as sociedades devem assegurar os direitos fundamentais, por meio de estruturas e organizações que não devem ignorar os direitos individuais, e que por sua vez, também não podem destituir os princípios da justiça presentes na sociedade o equilíbrio entre elas é fundamental. Em virtude dele, propõe-se reconhecer as diferenças como um elemento peculiar entre os indivíduos e sociedade, por isso, o princípio da diferença é essencialmente um princípio de reciprocidade, e por consequência, a substituição do princípio de igualdade por equidade, revelando e reconhecendo o 
Artigo original

Hegemonia - Revista Eletrônica do Programa de Mestrado em Direitos Humanos, Cidadania e Violência/Ciência Política do Centro Universitário Unieuro

ISSN: 1809-1261

UNIEURO, Brasília, número 26, Janeiro a Junho de 2019, pp. 4-29.

potencial das diferenças como novos direitos, ao exemplo das comunidades gays, em relação ao convívio marital e herança. Em especial, intrinsecamente, relativa às noções de identidade e reconhecimento dos distintos grupos que compõem a sociedade, sobretudo, pela valorização de suas idiossincrasias.

Dentro das ações consideradas básicas, a educação desponta como um instrumento em prol dos menos favorecidos e dos excluídos socialmente. Não se trata de uma concepção ingênua da educação como salvadora, mas em consonância com as discussões e reflexões desafiadoras de Severino (1986) que com maestria, retrata que a educação pode estar a favor das elites, como pode se constituir em uma ação contraideológica pelas classes em ascensão, quando assegura a qualidade dos saberes, o desnudar e a superação da contradominância do pensamento em vigente. Afinal, que projeto social ela (escola) deve reconhecer como um desafio e uma proposta a ser assumida?

Gonçalves (2017) espelha o desejo e os preceitos pertinentes à instituição escolar, ensejando que em uma perspectiva inclusiva e de diversidade cultural, todos devem agir em unicidade para tal propósito: gestores, professores, estudantes e funcionários e comunidade escolar externa. Reitera a urgência na formação docente em nível básico e na perspectiva continuada, assentando-se em uma "educação de todos para todos".

Consubustanciado a discussão, Shön (2000 apud NEIRA, 2016) defende que é essencial romper com as amarras do condicionamento, desvelando os motivos, os objetivos e as práticas de ações multiculturais, no espaço escolar, em forma de oposição e criticidade das estruturas já estabelecidas, projetando e introjetando uma forma de transformar os modelos e os padrões estagnados. O pensamento crítico-reflexivo, desafiador e contextualizado pode então, permitir a caracterização histórica das forças que produzem os códigos linguísticos e os signos, subjacentes às ideologias e às supremacias mundiais e hegemonia dos grupos dominantes em vários campos, como advogado por Freire (2002). 
Artigo original

Hegemonia - Revista Eletrônica do Programa de Mestrado em Direitos Humanos, Cidadania e Violência/Ciência Política do Centro Universitário Unieuro

ISSN: $1809-1261$

UNIEURO, Brasília, número 26, Janeiro a Junho de 2019, pp. 4-29.

No que tange a interculturalidade, Candau (2012) expressa que educação intercultural é um dos pilares na construção de sistemas educativos e das sociedades comprometidas com o processo democrático. Em especial, soerguidas sob o alicerce da equidade e do reconhecimento dos diferentes grupos socioculturais que os integram o ambiente social. $\mathrm{Na}$ linhagem do multiculturalismo crítico, a interculturalidade crítica se delineia, considerando as diferenças como inerentes a um processo instituinte das democracias, subsidiando novas interações e direitos entre os grupos que certamente asseguram os direitos aos excluídos historicamente.

A autora ainda distingue multiculturalismo e interculturalidade, acentuando que o primeiro se reporta a afirmação dos grupos no reconhecimento das suas peculiaridades e diferenças, enquanto que a segunda se baseia nas inter-relações que se estabelecem entre os diversos grupos culturais. Assim, nas práticas educativas, a discussão sobre as culturas afro-brasileiras, indígenas e quilombolas são exercícios importantes para os estudantes reconhecerem a diversidade do país, como reunidas e recuperada com riqueza e, profícua contextualizada, por Holanda (1997), em Raízes do Brasil.

Identidade cultural

É essencial administrar a discussão sobre identidade cultural e sua relação com os direitos humanos, interpretando-a do ponto de vista ideológico. Portanto, no que se refere à identidade cultural, emergem as concepções atreladas às divisões étnica, raciais, entre outras estabelece notadamente os limites entre o eu e o outro, reportando à categoria alteridade, já discutida neste texto. A contribuição da antropologia cultural recupera que os grupos sociais apresentam uma tendência a se autovalorizar e, em contrapartida, gerar perspectivas negativas em relação aos outros grupos, utilizando-se dos discursos de superioridade, civilidade, segregação, estereótipos e estigmas. 
Artigo original

Hegemonia - Revista Eletrônica do Programa de Mestrado em Direitos Humanos, Cidadania e Violência/Ciência Política do Centro Universitário Unieuro

ISSN: 1809-1261

UNIEURO, Brasília, número 26, Janeiro a Junho de 2019, pp. 4-29.

No livro 'Raízes do Brasil' (HOLANDA, 1997), em uma de suas passagens, é recuperado que ao negro foi negado a sua contribuição e valorização na constituição do país, pelo grau de preconceito e estigma, em relação ao seu grau de subserviência e escravidão imposta pelo colonizador, sendo desprezados e destituídos de valor na sociedade. Um dos impedimentos, reflete foi proibição do casamento entre as autoridades estrangeiras e esse grupo, em oposição, havia menos restrições e maior flexibilidade quanto ao casamento entre o colonizador branco e o índio e sua prole.

Assim, a etiquetagem na base do preconceito étnico-cultural-religioso vem se firmando por meio da intolerância, que para Carneiro (2001 apud PIERONI, FERMINO \& CALIMAN, 2014, p.23) fica explícita por meio das seguintes posturas:

multiplicação dos conflitos étnicos ou nacionais; a discriminação orientada a grupos minoritários; xenofobia que atinge: refugiados, exilados políticos, trabalhadores migrantes, comunidades flutuantes e imigrados; proliferação de organizações e ideologias racistas; aumento dos extremismos e dos fundamentalismos religiosos; acréscimo da violência contra símbolos intelectuais, escritores e líderes minoritários; fomento de intolerância por parte de movimentos e ideologias políticas que põem a culpa na criminalidade, na miséria; crescimento da intolerância contra marginalizados e socialmente excluídos, pertencentes a grupos vulneráveis.

$\mathrm{Na}$ atualidade, em nível nacional e internacional, tem-se observado o recrudescimento das diferenças, seja em relação aos refugiados de guerra na Europa, aos migrantes nos Estados Unidos, aos transgenêros na Rússia, ao aumento do feminicídio na Índia, à violência contra as mulheres, e ainda à exclusão da população indígena e de afrodescendentes no Brasil. Uma preocupação que aflige o espaço educativo no Brasil é a proposta da 'Escola sem Partido', também conhecida comumente como 'Lei da Mordaça' que percebe a instituição educacional apenas como um repositório de conhecimentos e não um lócus privilegiado da alteridade e diversidade humana, excluindo as dimensões do conflito, da diferença e da ação mediativa.

Substancialmente, reduz os estudantes à perspectiva de tabula rasa, privados de sentidos, conteúdos e experiências extraescolares, um sujeito acrítico, sem reflexão, bem como sem poder 
Artigo original

Hegemonia - Revista Eletrônica do Programa de Mestrado em Direitos Humanos, Cidadania e Violência/Ciência Política do Centro Universitário Unieuro

ISSN: 1809-1261

UNIEURO, Brasília, número 26, Janeiro a Junho de 2019, pp. 4-29.

de autonomia e autogestão de conhecimento, assim, um mero repetidor. Reiterada pela noção equivocada do sujeito sem ambiente, como o aluno vivesse sem referências de contexto local, nacional e mundial e impedindo o acesso às diversas formas de expressão cultural, social, afetiva, religiosa, política entre outras.

O que vem nas entrelinhas da escola sem partido, é a falsa neutralidade já superada por anos dentro do espaço acadêmico e científico, e está subjacente a possibilidade de controle do que vai ser abordado pelos professores, e até mesmo dos conteúdos e autores que fazem parte do universo de conhecimento, dos bens culturais, enfim uma escola empobrecida e deslocada do mundo. Em relação ao professor é lhe retirada a autonomia pedagógica em relação aos conteúdos, aos saberes e experiências, sobretudo, a educação não é vista como instrumento de intervenção no mundo e espaço de transformação, apenas de reforma e de repetição, tão amplamente criticada por Freire (2002). Equívocos e falta de clareza da proposta estão sendo apontados e discutidos em níveis nacional e internacional, em virtude da proposta não ter qualquer tipo de amparo científico e de pesquisa, apenas subsidiada pela opinião sem referências pedagógicas e crivada pelo senso comum de que a escola é neutra e, por conseguinte, sem posicionamento e sem reflexão crítica sobre o que acontece no país e no mundo. ${ }^{5}$

Considerando os retrocessos em relação a uma educação em direitos humanos, urge à adoção medidas em curto, em médio e em longo prazo, principalmente, no que tange às políticas públicas em saúde, educação, trabalho como também no fomento à reflexão da sociedade organizada, por meio das discussões, denúncias e intervenções balizadas contando com meios jurídicos, legais como a sensibilização do ambiente social. No sentido de combater posturas que ameacem à educação em direitos humanos e propor intervenções, Carneiro (2001 apud PIERONI,

\footnotetext{
5 https://educacao.estadao.com.br/noticias/geral,relatores-da-onu-denunciam-escola-sem-partido-e-classificamprojeto-de-censura, 70001737530
} 
Artigo original

Hegemonia - Revista Eletrônica do Programa de Mestrado em Direitos Humanos, Cidadania e Violência/Ciência Política do Centro Universitário Unieuro

ISSN: 1809-1261

UNIEURO, Brasília, número 26, Janeiro a Junho de 2019, pp. 4-29.

FERMINO \& CALIMAN, 2014) elenca várias propostas educacionais que podem efetivamente romper esse ciclo negativo de intolerância. Entre elas se destacam:

(a) Projetos educativos interculturais: subsidiados pela cultura para paz, ao permitir a escuta de outro e de si mesmo, incentivo aos potenciais comunicacionais assertivos, considerando a diferença como uma riqueza inestimável dos povos, de forma a identificar o capital presente no patrimônio cultura dos outros, ao assumir a diversidade como um imperativo ético e estético da humanidade. Sobretudo, adotando uma postura contraideológica ao autocentrismo cultural e superação crítica do sectarismo, revisão dos dogmas, preconceitos e estimas que perpassam as culturas e os grupos sociais como tarefas urgentes para a educação atual;

(b) educação em valores para interculturalidade: fomentada sob a égide dos valores universais explorada em diversos conteúdos e disciplinas, como Filosofia, História, Geografia, Antropologia, Sociologia, Psicologia, Língua Portuguesa entre outras que discutem cultura, grupos e sociedade;

(c) tolerância ativa: assumida pela ação em relação aos seus coetâneos como projeto de vida e de dimensão social, suplantando as fronteiras de raça, de condição, de língua, de etnia ou de religião. Na concepção de que tolerância não é incompatível com o sentimento de pertença, ao contrário, pressupõe o reconhecimento das noções de: nação, cultura, história, crença.

As dinâmicas educativas, as práticas presentes em seus currículos e espaço de ação favorecem a superação dos problemas identificados no que diz respeito a uma educação em direitos humanos. Em especial, propagando os princípios ligados à alteridade, às identidades plurais, aos valores individuais e coletivos, com um ensino calcado na cidadania e humanização, sustentando por uma postura multirreferencial em educação. Não assumindo ser a escola o epicentro das mudanças, entretanto, em colaboração com outros contextos sociais como de trabalho, vizinhança, comunidade, jurídico, etc. 
Artigo original

Hegemonia - Revista Eletrônica do Programa de Mestrado em Direitos Humanos, Cidadania e Violência/Ciência Política do Centro Universitário Unieuro

ISSN: 1809-1261

UNIEURO, Brasília, número 26, Janeiro a Junho de 2019, pp. 4-29.

Em suma, a discussão referente à construção das identidades de sujeitos 'invisibilizados' é extremamente necessária na sociedade atual para que se possa compreender e promover a equidade e a integração dos diferentes sujeitos socioculturais na nossa sociedade. Mas, ainda é necessário promover os diálogos interculturais para estimular a produção de projetos e atividades pedagógicas que abordem temáticas que contemplem a diversidade cultural, inseridas nas práticas escolares e na formação de professores, conforme abordado no próximo tópico.

Promovendo diálogos interculturais: a escola como um dos patrimônios da diversidade

A escola como um ambiente de diversidade e de acolhimento das diferenças necessita urgentemente organizar seus espaços curriculares, projetos e a comunidade próxima para a discussão sobre as pessoas, suas culturas, crenças, alteridade e direitos humanos. Várias experiências de sucesso e de interação da instituição escolar com distintos órgãos locais, nacionais e federais ilustram a intersetorialidade e a perspectiva de formação da cidadania e humanização, fundamentada na educação em direitos humanos.

No caso de Campo Grande, em 2015, o projeto que sela a ação multissetorial entre a Secretaria de Estado de Direitos Humanos e de Assistência Social e Trabalho, contando com o apoio da Superintendência de Direitos Humanos e, em parceria com a Secretaria de Estado de Educação, envolvendo alunos das escolas estaduais e universitários, na proposta de 'Direitos Humanos Vai à Escola'. Com o intuito de desenvolver em crianças, adolescentes e jovens, a consciência da realidade e de suas potencialidades, sob a égide da ética, cidadania e diversidade com 
Artigo original

Hegemonia - Revista Eletrônica do Programa de Mestrado em Direitos Humanos, Cidadania e Violência/Ciência Política do Centro Universitário Unieuro

ISSN: $1809-1261$

UNIEURO, Brasília, número 26, Janeiro a Junho de 2019, pp. 4-29.

referência na educação em direitos humanos, oportunizando informações e orientações a toda a população, sem qualquer restrição. ${ }^{6}$

Em Brasília, o projeto 'Maria da Penha Vai à Escola' tendo como núcleo a Escola de Aperfeiçoamento de Profissionais da Educação (EAPE), a partir da profícua parceria com o Tribunal de Justiça do Distrito Federal e Territórios (TJFT) e Centro Judiciário da Mulher (CJM) direcionado aos professores e monitores, destaca em seu objetivo:

oportunizar a formação de profissionais de educação para o trabalho de esclarecimento da comunidade escolar quanto aos direitos das mulheres em situação de vítimas de violência doméstica e família, sobretudo os direitos trazidos pela Lei Maria da Penha, e, ainda, para o trabalho de encaminhamento para rede de proteção às mulheres do DF. ${ }^{7}$

Nessa direção, Filha e Parente $^{8}$ descrevem a proposta de cooperação sedimentada por meio do 'Projeto Diversidade' de caráter interdisciplinar, envolvendo todas as escolas municipais de Esteio, no Rio Grande do Sul. As temáticas asseguram então resgate e valorização da cultura africana e da cultura indígena, bem como as relações de gênero e orientação sexual.

Vale ressaltar que o portal do Ministério da Educação ${ }^{9}$ (MEC), direcionado aos direitos humanos, enfatiza entre os vários programas fomentados o da 'Escola que Protege', com um manual de fácil acesso aos educares, ressaltando a promoção da saúde e a prevenção da violência contra crianças e adolescentes. Constitui-se em uma importante ação porque afeta os grupos em fase de desenvolvimento, alertando contra violações e desrespeito aos seus direitos, que gera inúmeros problemas, afetando aspectos cognitivos, psicoafetivos, de interação social e de sua própria maneira de ser no mundo. O foco é na formação de profissionais da educação básica para

\footnotetext{
6 http://www.sedhast.ms.gov.br/projeto-direitos-humanos-vai-a-escola-comemora-um-ano-com-a-marca-de-5-milatendimentos/

${ }^{7}$ http://www.eape.se.df.gov.br/maria-da-penha-vai-a-escola-para-professores-e-monitores/

$8 \quad$ https://www.feevale.br/Comum/midias/154b5d74-14cb-4539-8596-

eff2f7893fa1/Projeto $\% 20$ diversidade $\% 20$ educa $\%$ C3\%A7\%C3\%A3o $\% 20$ e $\% 20$ diretos $\% 20$ humanos.pdf

9 http://portal.mec.gov.br/observatorio-da-educacao/194-secretarias-112877938/secad-educacao-continuada223369541/13901-direitos-humanos
} 
Artigo original

Hegemonia - Revista Eletrônica do Programa de Mestrado em Direitos Humanos, Cidadania e Violência/Ciência Política do Centro Universitário Unieuro

ISSN: $1809-1261$

UNIEURO, Brasília, número 26, Janeiro a Junho de 2019, pp. 4-29.

a defesa incondicional da promoção do respeito e, concomitantemente, assegurar o direito e o combate a qualquer tipo de violência: física, psicológica e social.

Ainda no referido portal há um projeto ligado à 'Promoção do Reconhecimento da Diversidade Sexual e Enfrentamento ao Sexismo e a Homofobia', reconhecendo que os direitos desses grupos são constantemente ignorados, por meio da exclusão, preconceito e estigma, além da violência física constante. E por isso, o MEC, por meio da por meio da Secretaria de Educação Continuada, Alfabetização e Diversidade (Secad) tem assumido, em conjunto com as instituições de ensino, em seus diferentes níveis, ações e intervenções visando à valorização da identidade, da diversidade, permitindo e fomentado como direito a expressão afetivo-sexual. Aliado aos programas como Brasil sem Homofobia e o Plano Nacional de Promoção da Cidadania e Direitos Humanos de Lésbicas, Gays, Bissexuais, Travestis e Transexuais (LGBT), instaurando uma rede de apoio social e educacional direcionada às discussão sobre os problemas e às formas de intervenção psicossocial.

Outra experiência no espaço escolar é descrita por Almeida e Acker (2017), empregando a arte cinematográfica como promotora de reflexão sobre os direitos humanos na escola, por meio do projeto de extensão da Universidade Luterana do Brasil (ULBra), denominado 'Cine Diversidade', calcado na perspectiva da alteridade e experiências sobre alteridade. A proposta tem duas grandes vertentes: o cineclube e escola e, a elaboração de registros sobre direitos humanos e diversidade pelos alunos da escola. Filmes e documentários brasileiros foram selecionados para estudantes de $6^{\circ}$. ao $9^{\circ}$. ano, com o intuito de instrumentalizar professores e estudantes para posterior elaboração de materiais midiáticos sobre as questões de direitos humanos e as temáticas abordadas envolvem violência contra mulher, homofobia, bullying e haters na internet. 
Artigo original

Hegemonia - Revista Eletrônica do Programa de Mestrado em Direitos Humanos, Cidadania e Violência/Ciência Política do Centro Universitário Unieuro

ISSN: $1809-1261$

UNIEURO, Brasília, número 26, Janeiro a Junho de 2019, pp. 4-29.

Em Portugal, na mesma linha de ação, desenvolve-se o Projeto "Escolas Amigas dos Direitos Humanos” - Amnistia Internacional Portugal ${ }^{10}$ que assume o propósito de:

capacitar os jovens e promover a participação ativa de todos os membros da comunidade escolar para integrar os valores e princípios dos direitos humanos em todas as áreas da vida da escola, com destaque para as seguintes: governança; relações interpessoais; currículo e atividade extracurriculares; ambiente escolar.

Ressaltar-se que as ações pedagógicas do projeto supracitado estão fundadas nos dez princípios globais das escolas amigas dos direitos humanos, incrementando a não discriminação, a participação efetiva, a responsabilização social e a formação cidadã.

O destaque nesses projetos é a ação conjunta e unificada de vários órgãos e, também a estruturação de parcerias com as instituições escolares públicas e particulares. No sentido de compreender que a escola é promotora de saúde física e mental, assim como um espaço privilegiado de discussão, multiplicação e fomento às mudanças de comportamento, atitudes, e possibilita romper barreiras e preconceitos já instalados nas relações interpessoais. Sobretudo que, a escola sozinha não pode assumir essa tarefa tão complexa e que necessita de esforços de todas as áreas e que o sucesso também está ligado às parcerias, na constituição de uma rede de apoio e de ação multidisciplinar são essenciais para tecer os projetos e as possibilidades de intervenção.

Os casos citados acima são exemplos de ocorrência dessas transformações sociais, tanto quanto às questões relacionais e de estrutura organizacional, que são grandes focos de conflitos e desafios para o professor. Importante destacar e alertar que devido à complexidade dessas situações, que podem estar acima da capacidade de enfrentamento dos professores e da própria instituição escolar. Contudo, sem uma rede de apoio interinstitucional efetiva, os efeitos negativos são identificáveis nas condições de saúde dos profissionais de educação, como mal-estar docente ou até mesmo adoecimento, como níveis distintos de depressão, absenteísmo no trabalho, e o

\footnotetext{
${ }^{10} \mathrm{http}: / /$ www.dge.mec.pt/projeto-escolas-amigas-dos-direitos-humanos-amnistia-internacional-portugal
} 
Artigo original

Hegemonia - Revista Eletrônica do Programa de Mestrado em Direitos Humanos, Cidadania e Violência/Ciência Política do Centro Universitário Unieuro

ISSN: $1809-1261$

UNIEURO, Brasília, número 26, Janeiro a Junho de 2019, pp. 4-29.

próprio fracasso do processo de ensino e aprendizagem que atinge tanto professores e estudantes e os familiares

Com respeito aos discentes, Bertholino (2015) reitera que desde a educação infantil a educação em direitos humanos deve estar presente no currículo formal, nos momentos de informalidade, nas atividades lúdicas e nas discussões em sala. A condição de criticidade e o poder de reflexão devem ser estimulados, bem como intervenções pedagógicas que fomentem a interiorização dos princípios da solidariedade, do respeito às diferenças, da noção de equidade, das relações humanizadas e da cidadania com ações pedagógicas de acordo com as faixas etárias envolvidas. Principalmente, revelando nas discussões acontecimentos que afetam o sujeito e seu grupo como o desrespeito, segregação, da exclusão e da negação do outro como pessoa de direito, a serem suplantadas por uma prática e um projeto social de diversidade e inclusão.

A autora ainda ressalta que a escola deve ser preocupar como vai abordar as questões de valores e precisa compreender como ocorre sua introjeção e que práticas se estabelecem em relação ao outro. Nesse sentido, a formação dos docentes em nível de graduação e na educação continuada, associada a todo o corpo de profissionais da escola e, perpassada pela noção de responsabilidade social deve estar em pauta nos espaços educacionais. Sugere que a educação em direitos humanos deve, além de ser abordada em sala de aula, estar refletidas no processo inerente à gestão democrática, nos encontros e projetos com a comunidade e nas atividades extraescolares.

No entanto, a formação de multiplicadores entre os docentes, discentes e funcionários da escola, incluindo-se os parceiros da comunidade, torna-se um importante aliado para divulgação e promoção das relações positivas, humanas e saudáveis. Contudo, é fundamental empregar estratégias diversificadas que promovam a reflexão crítica, como a situação de se colocar no lugar do outro, perceber-se e perceber o outro em um dado contexto. Por isso, as metodologias 
Artigo original

Hegemonia - Revista Eletrônica do Programa de Mestrado em Direitos Humanos, Cidadania e Violência/Ciência Política do Centro Universitário Unieuro

ISSN: 1809-1261

UNIEURO, Brasília, número 26, Janeiro a Junho de 2019, pp. 4-29.

interativas e grupais são fundamentais para o desenvolvimento das atividades pertinentes à educação em direitos humanos.

Desafios: em busca de novas reflexões...

A Educação em Direitos Humanos é uma construção constante entre o sujeito e a sociedade, na intersecção entre pessoa, grupos, comunidades e cultura. A asserção da alteridade como um processo psicossocioeducativo permeia a ecologia dos saberes e da convivência, sustentáculos para o resgate do outro como sujeito em desenvolvimento e com suas idiossincrasias. A relação eu-outro é um par dialético presente em todas as sociedades e na interação humana, fomentado pela categoria alteridade. Destarte, as concepções filosóficas e postulados interligados à diversidade, identidade, multiculturalismo e interculturalidade que são pilares que na contemporaneidade devem estruturar transversalmente os currículos em todos os níveis educacionais.

Ordenado como temas transversais, a educação em direitos humanos, não é uma demanda ou está sob a custódia de uma disciplina, contudo, deve servir ao desenvolvimento de valores, comportamentos, atitudes e posturas cidadãs e com vista ao processo de humanização em todas as etapas de vida e ambientes sociais. Então, ela perpassa o âmbito da educação formal e se difunde para a não-formal, expandindo-se para os espaços de convivência humana, no trabalho, na vizinhança, no lazer e nas diversas circunstância de agrupamento humano.

$\mathrm{Na}$ concepção buberiana, o que antecede a relação Eu-Tu é o primado da relação marcada pela intersubjetividade, na ética da reciprocidade e do reconhecimento das diferenças como um potencial de desenvolvimento das pessoas e da sociedade (BUBER, 2004). Marcondes Filho (2008) reforça que a concepção da relação Eu e Tu na perspectiva buberiana, supera a descrição das 
Artigo original

Hegemonia - Revista Eletrônica do Programa de Mestrado em Direitos Humanos, Cidadania e Violência/Ciência Política do Centro Universitário Unieuro

ISSN: $1809-1261$

UNIEURO, Brasília, número 26, Janeiro a Junho de 2019, pp. 4-29.

atitudes do homem em relação ao outro e ao mundo, transcende a fenomenologia da palavra, e prioriza a ontologia da relação, uma celebração à alteridade. Todavia, revelada pelas interações contínuas e peculiares entre as pessoas, em seus papéis e funções sociais em relação aos valores, comportamentos e expectativas.

Nesse sentido, para enfrentar esses desafios, tanto a escola, como o próprio professor, devem e fortalecer os diálogos para viabilizar o entendimento do processo de construção das diferenças dentro da diversidade cultural presentes nas sociedades plurais, no intuito único e exclusivo de superar preconceitos culturais, incluir a apropriação das reivindicações e das lutas dos movimentos sociais e, principalmente, reconhecendo e fortalecendo a relação Eu-Tu e nesse espaço intercultural. Deve-se também serem ofertadas formações específicas para os professores com foco no trabalho com a diversidade, para prepará-los intelectual/cognitiva e emocionalmente para enfrentar essas temáticas.

Por essa razão, no ambiente educacional as polaridades, diferenças, divergências e conflitos devem se estabelecer e se revelar para serem continuamente trabalhadas e transformadas com a valorização do potencial humano, e a diversidade cultural associada à inclusão social, pedagógica, metodológica e atitudinal. Afinal, a educação como processo permanente de construção e de aprendizagem oportuniza essa utopia, no sentido proposto por Freire (2002), como uma intervenção no mundo e uma ação permanente. Nos projetos educativos devem emergir o sentimento de pertença, o reconhecimento das diferenças, de integração e de inclusão de sujeitos e grupos como bens humanos e essenciais para o desenvolvimento mundial que se inserem na perspectiva ampla da Educação em Direitos Humanos.

Contudo, defende-se a coresponsabilidade na educação em direito humanos, não sendo a escola a única fonte e local para se debater e vivenciar as diferenças. As parcerias devem ser celebradas, bem como a troca de experiências e entre os profissionais devem ser fomentadas e estimuladas para se tornar um projeto e uma ação coletiva de toda a sociedade brasileira. A 
Artigo original

Hegemonia - Revista Eletrônica do Programa de Mestrado em Direitos Humanos, Cidadania e Violência/Ciência Política do Centro Universitário Unieuro

ISSN: 1809-1261

UNIEURO, Brasília, número 26, Janeiro a Junho de 2019, pp. 4-29.

transformação e mudança de postura, abraçando a perspectiva da diversidade cultural, da inclusão escolar e social, tolerância, equidade, respeito e responsabilidade social pode ser desencadeada na escola, contudo, deve ser um objetivo a ser constantemente perseguido e atingindo por todas as instituições.

Referências

ALMEIDA, Gabriela Machado Ramos; ACKER, Ana Maria. O cinema como vivência dos direitos humanos na escola. REU, Sorocaba, v.43, n.12, p.247-260, 2017.

BERTHOLINO, Luana Silva. A importância dos direitos humanos como conteúdo escolar na construção da consciência crítica e cidadã dos alunos. 41st Association for Moral Educational Conference, Santos (São Paulo), 5 a 7 de novembro de 2015. Disponível em http://www.fecilcam.br/revista/index.php/anaisame/article/viewFile/1373/882, acesso em 03 de jul 2018.

BARREIRO, Guilherme Scodeler de Souza; FARIA, Guilherme Nacif de; SANTOS, Raíssa Naiady Vasconcelos. Educação em direitos humanos: uma tarefa possível e necessária. Educação em Perspectiva, Viçosa, v. 2, n. 1, p. 58-77, 2011.

BRASIL, Secretaria de Direitos Humanos da Presidência da República. Educação em Direitos Humanos: Diretrizes Nacionais, 2013.

BRONFENBRENNER, Urie. The bioecological theory of human development. In.: BRONFENBRENNER, U. (Ed.). Making human beings human: Bioecological perspectives on human development. California: Sage Publications, 2005, p. 3-14. 
Artigo original

Hegemonia - Revista Eletrônica do Programa de Mestrado em Direitos Humanos, Cidadania e Violência/Ciência Política do Centro Universitário Unieuro

ISSN: 1809-1261

UNIEURO, Brasília, número 26, Janeiro a Junho de 2019, pp. 4-29.

BUBER, Martin. Eu e Tu. Tradução, introdução e notas de Newton Aquiles Von Zuben. São Paulo: Centauro, 2004.

CANDAU, Vera Maria Ferrão. Diferença culturais, interculturalidade e educação em direitos humanos. Educação e Sociedade, Campinas, v. 33, n. 118, p. 235-250, 2012.

CARDOSO, João Casqueira. Os novos paradigmas dos direitos humanos e educação. In CALIMAN, Geraldo (Org.) Direitos Humanos na Pedagogia do Amanhã (pp.67-100). Brasília: Liber Livros, 2014.

COSTA, Alice Maria Lozano da. A Educação em Direitos Humanos e a convivência com as diferenças. Caderno Pedagógico, Ponta Grossa, Governo do Estado do Paraná, 2013.

COSTA, Jean Carlo de Carvalho; SOARES, Swamy de Paula Lima. Educação e pobreza: teoria da justiça como equidade e a política do reconhecimento.

FREIRE, Paulo. Pedagogia da autonomia. Saberes Necessários à Prática Educativa. 25ª Edição. São Paulo: Paz e Terra, 2002.

GONÇALVES, Angélica. Diversidade e inclusão na educação. Educere, Curitiba, XII Congresso Nacional de Educação, 2017.

JODELET, Denise. A alteridade como produto e processo psicossocial. In Arruda, Ângela (Org) Representando a alteridade (pp. 47-48) Petrópolis: Vozes, 1999.

HOLANDA, Sérgio Buarque. Raízes do Brasil. São Paulo: Companhia das Letras, 1997.

LIMA, Michelle Fernandes. A escola como lócus da diversidade. In SILVA, Adnilson José da et al. Fundamentos da diversidade e cidadania: percursos conceituais, históricos e escolares. Guarapuava: Editora da Premier/ Unicentro, 2009.

MARCONDES FILHO, Ciro. No diálogo com o outro, a crisálida pode tornar-se borboleta, a comunicação tem chance de acontecer: sobre Martin Buber. Em Questão, Porto Alegre, v. 4, n.1, p.95-105, 2008. 
Artigo original

Hegemonia - Revista Eletrônica do Programa de Mestrado em Direitos Humanos, Cidadania e Violência/Ciência Política do Centro Universitário Unieuro

ISSN: 1809-1261

UNIEURO, Brasília, número 26, Janeiro a Junho de 2019, pp. 4-29.

McLAREN, Peter A vida nas escolas: uma introdução à pedagogia crítica nos fundamentos da Educação. Porto Alegre: Artmed, 1997.

MENEGHETTI, Patrick Costa. Alteridade e educação em direitos humanos: um elo necessário. VII Mostra Acadêmica da FAMES, 2015. Disponível em http://fames.edu.br/mostraacademica/anais/viii-mostra-academica-da-fames/artigos/patrick-c-meneghetti.pdf, acesso em 15 jun 2018.

NEIRA, Marcos Garcia. O multiculturalismo crítico e suas contribuições para o currículo da Educação Física. Temas em Educação Física Escolar, Rio de Janeiro, v. 1, n. 1, p. 3-29, 2016.

OLIVEIRA, Gabriela Werner. A proteção internacional de minorias sexuais: entre a idade média e a pós-modernidade. Revista Direito Mackenzie, São Paulo, v. 9, n. 2, p. 113-128, 2017.

PREFEITURA DE GOIÁS. Secretaria Municipal de Saúde. Disponível em http://www.goiania.go.gov.br/sms/www.saude2/Html/Departamentos/conselho_municipal.ht m, acesso em 30 abr 2018.

PEREIRA, Célia Maria Rodrigues Costa. Diversidade cultural como um direito humano: desafio para a contemporaneidade. RIDH, Bauru, v. 4, n. 1, p. 97-114, 2016.

PESSOA, Ana Danielly Leite B; SANTOS, Auristela Rodrigues dos; CARVALHO, Maria Elizete Guimarães. A educação em direitos humanos para a efetivação do direito à memória e à verdade. RIDH, Bauru, v. 5, n. 1, p. 207-224, 2017.

PETRY, Alexandre Torres. Os direitos humanos como o principal critério de avaliação das instituições de educação superior. Avalies, Simpósio da Educação Superior, Porto Alegre, 17 a 18 de setembro, 2015.

PIERONI, Vittorio; FERMINO, Antonia; CALIMAN, Geraldo. Pedagogia da Alteridade: para viajar a Cosmópolis. Brasília: Liber Livro, 2014. 
Artigo original

Hegemonia - Revista Eletrônica do Programa de Mestrado em Direitos Humanos, Cidadania e Violência/Ciência Política do Centro Universitário Unieuro

ISSN: 1809-1261

UNIEURO, Brasília, número 26, Janeiro a Junho de 2019, pp. 4-29.

SANDOVAL, Mario. Educación en valores: una forma de contribuir a la promoción y defensa de los derechos humanos. In CALIMAN, Geraldo (Org.) Direitos Humanos na Pedagogia do Amanhã. Brasília: Liber Livros, 2014, p.35-63.

SEVERINO, Antônio Joaquim. Educação, ideologia e contraideologia. São Paulo: Educação Pedagógica e Universitária, 1986.

TARDIF, Maurice. A Pedagogia de amanhã ao longo do século 21. In CALIMAN, Geraldo (Org.) Direitos Humanos na Pedagogia do Amanhã. Brasília: Liber Livros, 2014, p.21-33..

WAINER, Jacques; MELGUIZO, Tatiana. Políticas de inclusão no ensino superior: avaliação do desempenho dos alunos baseado no Enade de 2012 a 2014. Educação e Pesquisa, São Paulo, v. 44, 2018.

WALLON, Henri. Do ato ao pensamento: ensaio de psicologia comparada. Textos Fundantes em Educação. Petrópolis, RJ: Vozes, 2008.

WENCESLAU, Maurinice Evaristo; TAVARES, Fabiany de Cássia Silva. Temas transversais ou conteúdos disciplinares? Cultura, cidadania e diferença. Interações, Campo Grande, v. 18, n. 4, p. 197-206, 2017. 